\title{
Pure and hybrid crowds in crowdfunding markets
}

\author{
Liang Chen ${ }^{1}$, Zihong Huang ${ }^{2}$ and De Liu $^{3^{*}}$ (D)
}

\footnotetext{
* Correspondence: deliu@umn.edu

${ }^{3}$ University of Minnesota, 3-163 Carlson School of Management, 321 19th Avenue South, Minneapolis, MN 55455, USA

Full list of author information is available at the end of the article
}

\begin{abstract}
Background: Crowdfunding has risen rapidly as a way of raising funds to support projects such as art projects, charity projects, and new ventures. It is very important to understand how crowds in the crowdfunding market are organized to carry out various activities. This study documents and compares two crowd designs for crowdfunding, namely pure crowds, where all crowd members participate as equals, and hybrid crowds, where crowd members are led by an expert investor. The hybrid design is rarely studied in the crowdfunding literature despite its large presence in equity crowdfunding.
\end{abstract}

Methods: We examine industry practices from various countries in terms of crowd designs, review relevant literature on this topic, and develop a conceptual framework for choosing between pure and hybrid crowds.

Results: We identify several inefficiencies of pure crowds in crowdfunding platforms and discuss the advantages of hybrid crowds. We then develop a conceptual framework that illustrates the factors for choosing between pure and hybrid crowds. Finally, we discuss the issue of how to manage and regulate lead investors in hybrid crowds.

Conclusions: Pure crowds have several shortcomings that could be mitigated by a hybrid crowd design, especially when the proposed project suffers from greater risks, a high degree of information asymmetry, concerns about information leakage, and a high cost of managing the crowds. But for the hybrid crowd to work well, one must carefully design mechanisms for lead investor selection, compensation, and discipline. Our study contributes to the crowdfunding literature and to crowdfunding practice in multiple ways.

Keywords: Crowdfunding, Wisdom of the crowds, Crowd design, Lead investor, Syndicate

\section{Background}

Over the past 10 years, crowdfunding has risen rapidly as a popular way of raising funds to support projects such as small personal loans, new product development, art projects, charity projects, and new ventures. Crowdfunding removes traditional financial intermediaries and lets project creators directly appeal to investors through an Internet platform. As a funding platform, the Internet has undeniable appeal in terms of reaching a large crowd of small investors ${ }^{1}$ and supporting efficient information dissemination and transaction processing. Amid this disintermediation is the unprecedented reliance on

(c) The Author(s). 2016 Open Access This article is distributed under the terms of the Creative Commons Attribution 4.0 International License (http://creativecommons.org/licenses/by/4.0/), which permits unrestricted use, distribution, and reproduction in any medium, provided you give appropriate credit to the original author(s) and the source, provide a link to the Creative Commons license, and indicate if changes were made. 
crowds, defined as a large number of non-experts, for tasks such as gathering project information, evaluating project risks, and deciding whether a project should be funded.

Although the phenomenon termed the "wisdom of the crowds," defined as when a collection of non-experts outperforms a few experts, has often been found to occur when judgment and prediction tasks are carried out, the total reliance on crowds does pose several issues for crowdfunding. For instance, an average crowd member may be either unqualified or unwilling to conduct the due diligence necessary for evaluating project risks. Managing many crowd investors can also prove to be unwieldy for most project creators. These limitations raise an important question about the use of crowdfunding: how can we design crowds to avoid their common shortcomings?

Based on the foregoing, this study explores the issue of crowd design for crowdfunding, particularly how crowds are organized in a crowdfunding market to carry out various activities. Based on industry practices, it focuses on two popular forms of crowd designs: pure crowds, where all investors in the crowd participate as equals, and hybrid crowds ${ }^{2}$, where a crowd of investors are led by an expert investor.

A pure crowd design requires the crowd members to play many roles in a crowdfunding platform, including supplying funds, choosing and evaluating projects, gathering project information, and monitoring and promoting a project. However, several barriers prevent an unorganized crowd from fulfilling some of these roles. First, some activities such as due diligence are "public goods" in the sense that efforts by one crowd member can benefit others. A common problem associated with the private provision of public goods is the "tragedy of the commons," where an individual member has insufficient incentives to carry out an activity that benefits others (Adar and Huberman 2000; Krishnan et al. 2003). Moreover, relying on the wisdom of the crowds has limitations for evaluating the merits of a project. Because crowd members are not generally experts, they infer project quality by observing the decisions made by their peers (Zhang and Liu 2012). A lack of independence undermines the wisdom of the crowds, causing biases and large uncertainties in the outcome (Salganik et al. 2006; Lorenz et al. 2011). Finally, when a project faces tens of hundreds of crowd investors, managing and communicating with crowd members becomes cumbersome and inefficient.

A syndicate of investors led by an expert lead investor might provide a good solution to overcome the limitation of pure crowds (Deschler 2013). Unlike smaller investors in the crowd, a lead investor is generally highly knowledgeable about valuing risky projects and ventures. Lead investors have the incentives (their get a share of profit from successful projects) and expertise to carry out costly activities such as due diligence, project monitoring, and brokering the communication between project creators and crowd investors.

The question of crowd design has been explored in various studies. For example, the literature on prediction markets has studied the aggregation rules and incentive schemes used to assimilate the opinions of a crowd to provide the most accurate prediction. Studies have also investigated how to design voting rules for crowd-based voting. However, this study departs from the aforementioned work in two important ways. First, we examine a different context (i.e., crowdfunding), which has distinct tasks and goals. Second, we study the hybrid crowd design for the first time in this strand of the literature. Through this work, we aim to answer two important questions: how should we choose between pure and hybrid crowds and if a hybrid crowd is used, how should we manage the lead investors? 
The remainder of the paper proceeds as follows. Industry Background discusses industry practices in terms of crowd designs and Related Literature reviews the relevant literature on this topic. Based on our observations, we propose several factors that may favor one or other type of crowd design in Use of Pure and Hybrid Crowds. Managing Lead Investors discusses the managerial and regulation issues associated with managing the lead investors in the crowd. Finally, Conclusion concludes the paper and offers future research directions.

\section{Industry background}

While all crowdfunding platforms rely on crowd participation, the ways in which crowd members participate in the funding processes differ, especially regarding whether they are guided by lead investors. To understand different crowd designs, we investigate four types of crowdfunding platforms (Wilson and Testoni 2014): donation-based, lendingbased (also known as peer-to-peer lending), reward-based, and equity-based (see Table 1). We pay special attention to how each type of platform organizes the crowd, especially

Table 1 Examples of Crowdfunding Platforms

\begin{tabular}{|c|c|c|c|c|c|c|c|}
\hline $\begin{array}{l}\text { Crowdfunding } \\
\text { platform }\end{array}$ & Location & Type & $\begin{array}{l}\text { Amount } \\
\text { raised }\end{array}$ & $\begin{array}{l}\text { Number of } \\
\text { ventures }\end{array}$ & $\begin{array}{l}\text { Number of } \\
\text { investors }\end{array}$ & $\begin{array}{l}\text { Crowd } \\
\text { design }\end{array}$ & $\begin{array}{l}\text { Platform } \\
\text { involvement }\end{array}$ \\
\hline $\begin{array}{l}\text { AngelList https:// } \\
\text { angel.co/ }\end{array}$ & US & Equity & $\$ 445 M$ & 200 & - & $\begin{array}{l}\text { Hybrid } \\
\text { (Syndicate) }\end{array}$ & $\begin{array}{l}\text { Join syndicate, } \\
\text { get } 5 \% \text { carry }\end{array}$ \\
\hline $\begin{array}{l}\text { Yuanshihui http:// } \\
\text { yuanshihui.com/ }\end{array}$ & China & Equity & $¥ 200 M$ & 150 & 20,000 & Pure & Risk warning \\
\hline $\begin{array}{l}360 \text { Taojin https:// } \\
\text { t.360.cn/ }\end{array}$ & China & Equity & $¥ 304 M$ & 7 & - & Pure & - \\
\hline $\begin{array}{l}\text { CrowdCube https:// } \\
\text { crowdcube.com/ }\end{array}$ & UK & Equity & $£ 188 \mathrm{M}$ & 449 & 306,958 & Pure & $\begin{array}{l}\text { Investment } \\
\text { education (Quiz) }\end{array}$ \\
\hline $\begin{array}{l}\text { Seedrs https:// } \\
\text { www.seedrs.com/ }\end{array}$ & UK & Equity & $£ 150 M$ & 380 & - & Pure & $\begin{array}{l}\text { Investment } \\
\text { education (Quiz) }\end{array}$ \\
\hline $\begin{array}{l}\text { CircleUp https:// } \\
\text { circleup.com/ }\end{array}$ & US & Equity & $\$ 275 \mathrm{M}$ & 205 & - & Pure & - \\
\hline $\begin{array}{l}\text { ASSOB https:// } \\
\text { assob.com.au/ }\end{array}$ & Australia & Equity & $\$ 145 M$ & - & - & Pure & Due diligence \\
\hline 36kr https://36jr.com/ & China & Equity & - & - & - & Hybrid & Risk warning \\
\hline $\begin{array}{l}\text { JD Dongjia https:// } \\
\text { dj.jd.com/ }\end{array}$ & China & Equity & $¥ 1,280 \mathrm{M}$ & 107 & 76,104 & Hybrid & - \\
\hline $\begin{array}{l}\text { AngelCrunch http:// } \\
\text { angelcrunch.com/ }\end{array}$ & China & Equity & - & - & - & Hybrid & - \\
\hline $\begin{array}{l}\text { Kickstarter https:// } \\
\text { kickstarter.com/ }\end{array}$ & US & Reward & $\$ 2,651 \mathrm{M}$ & 113,220 & $11,736,206$ & Pure crowd & Risk warning \\
\hline $\begin{array}{l}\text { Indiegogo https:// } \\
\text { indiegogo.com/ }\end{array}$ & US & Reward & - & - & - & Pure crowd & - \\
\hline $\begin{array}{l}\text { Zhongchou http:// } \\
\text { zhongchou.com/ }\end{array}$ & China & Reward & - & - & - & Pure crowd & - \\
\hline $\begin{array}{l}\text { Lending Club https:// } \\
\text { lendingclub.com/ }\end{array}$ & US & Debt & $\$ 22 B$ & - & - & Pure crowd & Risk warning \\
\hline $\begin{array}{l}\text { Prosper https:// } \\
\text { prosper.com/ }\end{array}$ & US & Debt & $\$ 6 B$ & - & - & Pure crowd & Risk warning \\
\hline $\begin{array}{l}\text { FirstP2P https:// } \\
\text { firstp2p.com/ }\end{array}$ & China & Debt & $¥ 139 \mathrm{~B}$ & $60,513,414$ & $3,105,548$ & Pure crowd & Risk Warning \\
\hline $\begin{array}{l}\text { GoFundMe https:// } \\
\text { gofundme.com/ }\end{array}$ & US & Donation & $\$ 3 B$ & - & - & Pure crowd & - \\
\hline
\end{tabular}


whether it formally provides lead investors, as well as examine information on type of crowdfunding platform, services offered, size, and location.

\section{Pure crowds}

We use "pure crowds" to refer to the straightforward crowd design in which crowd members participate as equal investors (i.e., no one member assumes the formal role of the lead investor). Kickstarter (https://www.kickstarter.com/) is a good example. Each crowd member on Kickstarter can use the platform to browse or search for projects. For each project, members can view the project profile and receive signals of progress such as the percentage of funding and number of existing investors. The platform also provides a Q\&A area for potential investors to ask project creators questions. A potential investor can combine these signals and his/her own judgment to decide whether to invest in the project. On some platforms, social networking tools are available for investors (Liu et al. 2015; Zhang and Liu 2012), although any "following" stays informal: the followed do not assume special responsibilities or receive any explicit reward.

The pure crowd design is popular among crowdfunding platforms, especially rewardbased ones. Other examples of pure crowds include IndieGoGo (https://www.indiegogo. com/), as well as regional platforms such as ZhongChou (http://www.zhongchou.com/), a leading crowdfunding platform in China. Even among the more complex equity-based crowdfunding platforms, the pure crowd design is still popular, such as 360 Taojin (https://t.360.cn/) in China, CowdCube (https://www.crowdcube.com/) and Seedrs (https://www.seedrs.com/) in the United Kingdom, CircleUp (https://circleup.com/) in the United States, and ASSOB (https://assob.com.au/) in Australia.

\section{Hybrid crowds}

Hybrid crowds use lead investors, which are described as "well-versed, experienced investors who spend the time conducting due diligence on a venture, and invest a large amount in an equity crowdfunding campaign" (Rose 2016). Lead investors perform several roles in the crowdfunding process such as identifying projects and bringing them to the platform, conducting due diligence on projects, reporting to crowd investors, promoting a crowdfunding campaign, monitoring an ongoing project, and providing followers with project updates. Lead investors are also required to invest a significant proportion of the total investment amount to signal their commitment to and confidence in the project. Crowd investors often choose projects based on whether it is backed by a lead investor as well as what the lead investor says about the project.

However, although lead investors perform many of the roles typically carried out by traditional financial intermediaries (e.g., banks, charity organizations, venture capitalists), there are several differences between the two types. First, lead investors are selected from the crowd; indeed, any accredited investor on platforms may become the lead. Further, lead investors supplement rather than replace direct investments by crowd members. The two coexist in a hybrid crowd (whereas some traditional financial intermediaries may preclude direct investments).

Hybrid crowds are currently only seen in equity-based crowdfunding. In fact, hybrid crowds are widely employed in equity crowdfunding. For example, 36kr (https://www.36jr.com/), a Beijing-based equity-based crowdfunding platform, 
provides all the features of a pure crowd design including funding progress, a Q\&A area, and project profile pages in addition to a formal lead investor. After a project is posted online, an investor, often an institutional investor, may apply to become the lead investor for the project. The platform delegates the task of choosing the lead investor to the project creator. If the project is successfully funded, the lead receives a small percentage, usually $2 \%$, of the total amount raised as a service fee.

After the project is successfully funded, the lead investor and his or her co-investors form a Limited Liability Partnership company with the lead playing the role of the General Partner and the rest serving as Limited Partners. When the project exits from the venture, by way of compensation for lead investors' efforts and the risk they take, they are often paid in the form of a "carry," that is, a proportion of the total exit profits (typically around $20 \%$ ). Hence, lead investors serve as a catalyst for unlocking investment from others because the commitment and endorsement from a lead investor gives confidence to other crowd investors.

In addition to 36kr, other examples of hybrid crowds are JD Dongjia (https://dj.jd.com/) and AngelCrunch (http://angelcrunch.com/). AngelList, a world-renowned equity-based crowdfunding platform, implements a variation of the hybrid crowd design, where lead investors, instead of project creators, bring projects to the platform. Lead investors and their co-investors form a syndicate with the purpose of making a single investment (e.g., in a tech startup). Crowd investors can then apply to join one or several syndicates. If a syndicate exits from its investment, $5-20 \%$ of total profits will go to the lead investor and $5 \%$ to the platform.

The hybrid crowd design is not limited to crowdfunding platforms. An Israel-based social trading platform called eToro also institutes a lead investor scheme on its trading platform. Traders on this platform can follow "popular investors" and copy their trading strategies, and popular investors are rewarded with a fixed payment up to $2 \%$ of their annual assets for the copiers they attract.

\section{Related literature}

\section{Crowdfunding}

Crowdfunding is a relatively new way of collecting small amounts of funding by directly appealing to potential investors via the Internet. It often requires investors to judge project risks. Research suggests that risk judgment associated with loans and ventures may require special knowledge and expertise (Diacon 2004; Glaser and Weber 2007). However, individual investors in a pure crowd typically invest relatively small amounts of money and receive a relatively small stake of a company in return (e.g., Malmendier and Shanthikumar 2007). Thus, they may not have the necessary expertise to reach a high-quality risk judgment.

To compensate for the lack of "wisdom" of an average crowd member, the platform often leverages the wisdom of the crowds by, for example, instituting a "provision point mechanism" such that project creators will not receive funds unless the target investment is reached (Agrawal et al. 2013; Belleflamme and Lambert 2014). Crowdfunding platforms allow individual investors to leverage the wisdom of the crowds through observational learning (Zhang and Liu 2012), by highlighting the number of existing 
investors and overall progress towards the funding goal (Ahlers et al. 2015). However, the wisdom of the crowds is not without its limitations, as discussed in Pure Crowds and the Limitations of the Wisdom of the Crowds.

Crowdfunding is an example of a two-sided market with project creators on one side and investors on the other. As with many two-sided markets, information asymmetry is one of the largest barriers to market efficiency and liquidity. Crowdfunding investors still face great uncertainty about the quality and authenticity of projects because insufficient information about projects may be available and it may be difficult to authenticate the voluntary information disclosed by project creators.

Crowdfunding platforms adopt different strategies to gather information and reduce this high level of information asymmetry. Some platforms dispatch employees to work with project creators to gather information and ascertain their authenticity. Others set up branches and local offices, and act more like a traditional bank. However, each of these remedies requires investment in capital and human resources to support offline activities, which can severely limit the scalability of online crowdfunding platforms. When crowdfunding platforms incur these overheads, they are also in more direct competition with traditional intermediaries.

A hybrid crowd offers another way of alleviating information asymmetry. By crowdsourcing the due diligence and other necessary functions to lead investors, the crowdfunding platform can continue to function as an online platform. In this way, lead investors can fulfill the roles that an average crowd member is unwilling or unable to do. By investing significantly in a project, a lead investor can also boost investor confidence and increase the liquidity of crowdfunding markets. We discuss the literature on pure and hybrid crowds in more detail in the next two subsections.

\section{Pure crowds and the limitations of the wisdom of the crowds}

A pure crowd design, the original concept of crowdfunding, has received the most research attention on this topic. By leveraging the wisdom of the crowds, pure crowds can work well in certain market conditions. In terms of the quality of investment decisions, Mollick and Nanda (2016) find a significant agreement between the funding decisions of crowds on Kickstarter (a pure crowd platform) and those of the experts they surveyed. In terms of judging project quality, Mollick (2014) finds that crowd investors largely respond to quality signals and suggests that their crowdfunding decisions are linked to the chance of a project succeeding.

However, a pure crowd design has some limitations. In a pure crowd, investors assume that prior investment decisions are justified by private information, and thus consider accumulated capital to be a quality signal. Consequently, they may decide to imitate prior decisions, leading to "herding" behavior (Zhang 2013; Zhang and Liu 2012; Agrawal et al. 2013; Vismara 2015). However, herding could be a double-edged sword. On the one hand, it could be rational if based on observational or social learning. A thoughtful investor can draw useful inferences by combining peer investment decisions and publicly observable project characteristics. Zhang and Liu (2012) and Kim and Viswanathan (2014) find that rational herding exists in crowdfunding. On the other hand, herding behavior could also be irrational because investors are afraid to lose the opportunity to invest and blindly follow prior investors without questioning the soundness of their judgments (Moritz et al. 
2015). Even when it is rational to herd, the investor could still suffer a loss, as prior decisions may contain little to no information (Banerjee 1992).

Second, the cascade of information from early investors to later ones could be manipulated, especially when non-quality factors such as friendship and reciprocity are involved in the early stage of a fundraising process. For instance, Hekman and Brussee (2013) find that a person with high social capital, regardless of the quality of his or her project, is more likely to successfully raise funds on Kickstarter. Furthermore, Liu et al. (2015) show that friends of the project creators on PPDai, especially close offline friends, act as financial pipes by fund money. Zvilichovsky et al. (2013) also find that reciprocity exists on Kickstarter: a project owner's backing history has a significant effect on his or her financing outcomes. They also find that projects created by active investors have higher success rates, attract more investors, and collect more funds. Agrawal et al. (2013) point out that friends and family disproportionately invest early in the funding cycle, generating a signal for later investors through accumulated capital. Without conducting an objective and accurate assessment of project quality, these non-quality factors can thus lead to biased judgments, causing inefficient fund allocation.

The third issue with the pure crowd design is home bias, that is, the effect of geography (Lin and Viswanathan 2015). Agrawal et al. (2013) point out that funding in non-equity crowdfunding is not geographically constrained. Agrawal et al. (2011) find that the average distance between artists and investors on Sellaband is about 3,000 miles and that $86 \%$ of funds come from individuals more than 60 miles away from the project creator, suggesting a reduced role for spatial proximity. They attribute this geographic effect to the fact that investors are willing to have a personal connection with the project creators (the social effect). However, by using data from Prosper.com and employing a quasi-experimental design, Lin and Viswanathan (2015) find evidence that home bias still exists in crowdfunding. Unlike Agrawal et al. $(2011,2015)$, they find that such home bias cannot be fully explained by the social effect. They further demonstrate that economic motivations (e.g., higher expected returns) alone cannot explain home bias and that behavioral motivations such as familiarity with the home state, emotional attachment, and simple homophily play an important role. Thus, home bias could be rational (physical proximity facilitates information acquisition) or irrational (emotional attachment or hindrance).

Surowiecki (2004) suggests that the wisdom of the crowds requires three key conditions: the crowd must be diverse, its members must be independent, and it must have a particular kind of decentralization. To fully achieve the wisdom of the crowds, a crowd should make independent decisions, free of predecessors' investment decisions, cognitive bias, emotional hindrance, and psychological influence (Lin and Viswanathan 2015). However, in practical pure crowd designs, these assumptions are inevitably violated, raising questions about the efficiency of the pure crowd design.

Finally, pure crowds can also suffer from information asymmetry because of the high cost of conducting due diligence. For example, Agrawal et al. (2016) compare syndicated and non-syndicated deals on AngelList and find that syndicates enhance economic growth by reducing market failures and allocating capital more efficiently because they significantly reduce the information asymmetry problem.

Deschler (2013) also points out the potential problem of liquidity in pure crowds: a crowd of investors with voting power in equity crowdfunding emits a warning signal for professional investors who might otherwise have bought into a crowdfunded 
company. However, the author demonstrates that a syndicate could be a good solution to the liquidity problem because all crowdfunding investors would be rounded into a single vehicle with a professional manager ensuring that investors' voices are heard as well as keeping the business attractive to future rounds of financing. All these limitations suggest that an alternative crowd design may be required.

\section{Hybrid crowds}

The literature on hybrid crowds is scarce compared with pure crowds. Overall, hybrid crowds with lead investors embrace the key success factors shared among successful venture capital firms while leveraging the benefits of crowdfunding (Coppey 2016). Lead investors in a hybrid crowd are generally highly knowledgeable about valuing startups and assessing founding teams compared with small investors. Furthermore, relative to their investments, the costs for lead investors to conduct due diligence (e.g., evaluating project ideas and teams) are small (Ahlers et al. 2015).

Despite these benefits of hybrid crowds, however, costs and challenges are associated with this design. First, lead investors typically take a $20 \%$ cut from the total profits, which adds a significant cost. Second, Deschler (2013) cautions that while the idea of a syndicate seems relatively straightforward, this is a complicated area of financing. Once seasoned veterans of venture capital and their lawyers are brought in as lead investors, unsophisticated investors stand at a significant disadvantage. In addition, many open questions remain for platforms and policymakers, such as how to identify, compensate, and discipline lead investors as well as how to prevent lead investors from colluding with project creators.

\section{A framework for choosing between pure and hybrid crowds}

Crowdfunding is an example of a two-sided market in which project creators and investors meet to create value by funding high-quality projects (see Fig. 1). For this to happen, several steps are necessary. First, a project needs to be identified, which is followed by gathering project information. Once the project is launched online, its information is disseminated among potential investors, who then evaluate projects and decide whether to invest in it. If the project reaches its funding goal, it may be monitored to ensure the successful delivery of the promised benefits to investors. Each of these steps may require the participation of one or several stakeholders including the platform, the project creator, and investors. For example, information gathering may occur through voluntary disclosure by the project creator or independent research by the platform or investors.

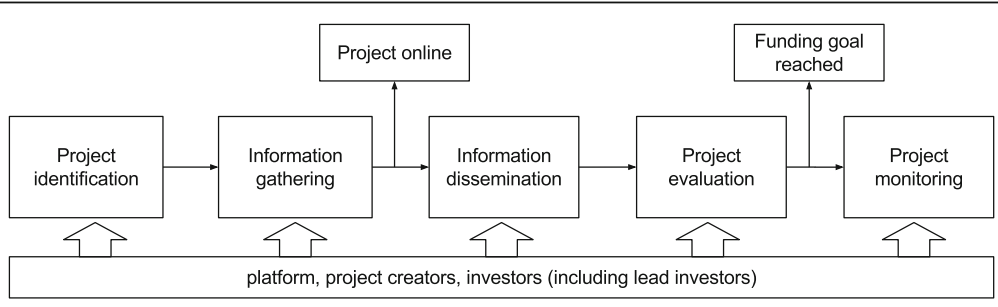

Fig. 1 Crowdfunding Process 
The goal of crowdfunding is to successfully and efficiently fund projects worthy of investment. A good crowdfunding platform should thus help worthwhile projects collect the desired funds and produce (tangible or intangible) returns to investors as well as the platform; a good platform should also filter out unworthy and fraudulent projects. However, the inherent information asymmetry among project creators, investors, and the platform may lead to inefficient funding outcomes including failing to fund a worthy project and/or funding an unworthy one. Non-negligible transaction costs in the aforementioned steps may also prevent worthy projects from being funded.

Whether a crowdfunding project could benefit from a pure or hybrid crowd design depends on the transaction costs and degree of information asymmetry at the different stages of crowdfunding as well as on whether adequate remedies are in place to overcome such challenges. As presented in Fig. 2, we propose a framework for choosing between pure and hybrid crowd designs, organizing the potential driving factors of the crowd design choice by stakeholders: project creators, the platform, and investors. This framework may be relevant for investors (i.e., the choice of investing in a pure or hybrid crowd platform or project), project creators (i.e., the choice of launching their campaign on a pure or hybrid crowd platform), and platforms (i.e., the choice of crowd design).

\section{Project creator factors}

The characteristics of the project and its creators can play a significant role in choosing the most appropriate crowd design. Next, we consider four major factors: project risk, information availability, information leakage, and the cost of managing the crowd.

\section{Project risk}

From the perspective of an investor, the project is riskier if it demands a larger and longerterm investment, is at an early stage of development, or involves a highly innovative product or service whose market potential is uncertain. Many early-stage projects and ventures fall into the category of high-risk projects (Agrawal et al. 2013; Ahlers et al. 2015).

When a project is risker, it demands more due diligence. While a pure crowd may work when the cost of due diligence is small, the presence of a lead investor would work better if heavy-duty due diligence is required. Moreover, assessing a risky project requires a great deal of expertise (Diacon 2004; Glaser and Weber 2007). Crowd investors may not have the same level of expertise as lead investors. Indeed, experts' specialist knowledge or skills

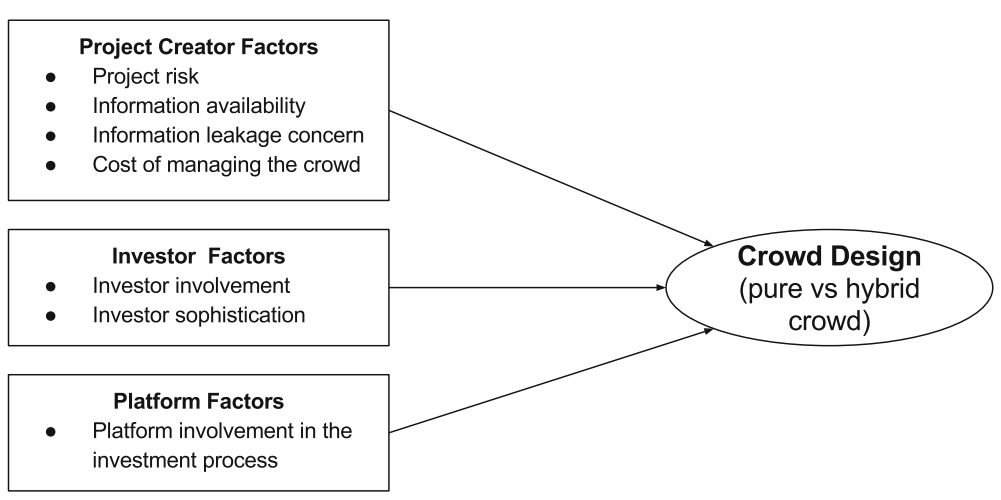

Fig. 2 A Framework for Choosing between Pure and Hybrid Crowds 
should make them better problem-solvers than non-experts, particularly in a complex and dynamic environment Fuglseth and Grønhaug (1995). For example, Byrne (2005) reveals that experts exhibit a positive correlation in risk-return judgments, whereas novices show no such correlation. Moreover, when a project's risk is high, crowd investors are reluctant to invest; hence, having an expert lead investor raises the confidence of crowd investors. In sum, we propose:

Proposition 1 The riskier a project is, the more advantageous a hybrid crowd is over a pure crowd.

\section{Information availability}

Project creators must provide the basic information required by the government and the crowdfunding platform. In addition, project creators may disclose other information such as industry trends, product information, and risk information. Previous research (Lewis 2011; Ahlers et al. 2015) has shown that information disclosure is an important success factor in two-sided markets because this can reduce information asymmetry. For example, Ahlers et al. (2015) find that providing more detailed information about risks can be interpreted as an effective signal that can increase the likelihood of funding success.

However, the amount of information available for disclosure depends on the project. For new projects and "small-time" entrepreneurs, insufficient information and historical data might be available; by contrast, repeated projects can have more demonstrable information. In some countries, hard data such as credit scores are available for disclosure. Moreover, early-stage projects have less information to disclose than late-stage projects.

A lack of project information poses a greater threat to pure crowds because of the tragedy of the commons. When more information about a project or its creator is available, pure crowds operate effectively and save the cost of deploying an intermediary. By contrast, in a limited information environment, a hybrid crowd is more likely to succeed by paying an intermediary to gather the necessary information. Thus:

Proposition 2 The less information on a project available, the more advantageous a hybrid crowd is over a pure crowd.

\section{Information leakage}

When project creators are required to disclose their innovations or sensitive information in a public forum, they may be disincentivized because their innovations could be imitated or stolen by their competitors, especially during the fundraising period (Agrawal et al. 2013). The risk of information leakage is reduced in the hybrid crowd design, where sensitive information can be disclosed to a single lead investor who can then assess it and provide a verdict to crowd investors without disclosing the actual information. Therefore, when project creators perceive a higher risk of information leakage, they may prefer a hybrid crowd over a pure one.

This concern about information leakage may vary across project types and stages. Some projects such as concerts and commercials can benefit from information leakage because they can then attract more word-of-mouth before their formal launch. However, other projects such as high-tech startups involve intellectual properties that are 
easily imitable; hence, their project creators may hesitate to launch their campaigns to a pure crowd for fear of laying bare their innovation to the public. Hence:

Proposition 3 The higher the concern about information leakage, the more advantageous a hybrid crowd is over a pure crowd.

\section{Cost of managing the crowd}

In a pure crowd, project creators must manage many investors. Directly engaging a large crowd is not without its costs. Crowds may raise many questions about a project that need to be answered in a timely manner. In reward-based crowdfunding, delivering the rewards to each investor can be a great hassle to a project creator. Wortham (2012) records that project creators can spend too much time answering emails and making T-shirts for their investors, leaving too little time to build the software. Allowing the entire crowd to monitor an ongoing project after its successful funding is also inefficient since the creator may need to respond to repeat inquiries. This process can be extremely costly as the number of investors rises (Agrawal et al. 2013). By contrast, it is more efficient for the project creator to engage the crowd through a single voice, namely the lead investor. Hence, as hybrid crowds remove the direct interaction between investors and project creators, the latter can focus on their core business. Hence:

Proposition 4 The higher the cost of managing the crowd, the more advantageous a hybrid crowd is over a pure crowd.

\section{Investor characteristics}

The characteristics of investors may also influence the choice between pure and hybrid crowds. We consider several investor-specific factors, including desirable investor involvement and the cost of information acquisition and processing.

\section{Desirable investor involvement}

The decision-making process of venture capital investment is time-consuming and labor- intensive because a lot of information must be collected and analyzed and several rounds of evaluation should be conducted before a proposal is funded (Fried and Hisrich 1994). Although the Internet facilitates information gathering and processing, investors still face great challenges given the large number of projects available. In some crowdfunding projects, investors may thus need to be willing to forgo some return in exchange for less involvement in the project selection and evaluation. In others, they may be more willing to take on such roles. Hence:

Proposition 5 The higher the desirable involvement of investors in the investment process, the less advantageous a hybrid crowd is over a pure crowd.

\section{Cost of information acquisition and processing}

Financial investment is a complex decision, and it takes time and resources to acquire and process information, especially when an investor has limited investment experience and knowledge. Owing to the information asymmetry between investors and project creators, the former must acquire and process additional information. Further, investors may not believe all the information provided by the project creator and may need to double check such information. In addition, although some information such as 
industry trends and market potential is a public good, investors may not want to collect this because of the possibility of free riding (Agrawal et al. 2013; Zhunussov 2015). If it is costly for individual investors to acquire and process investment information (because of their incapability or unwillingness, or the high opportunity cost), an intermediary could be recruited; under this arrangement, each individual investor need only pay a small amount of money for the information acquired, analyzed, and disclosed by the intermediary. Thus,

Proposition 6 The higher the level of investor sophistication, the less advantageous a hybrid crowd is over a pure crowd.

\section{Platform}

We have thus far proposed that recruiting a lead investor can overcome the information asymmetry and transaction cost problems associated with crowdfunding processes. However, lead investors are not the only party that can provide these services. Indeed, the platform itself can serve some, if not all, of these roles.

\section{Platform involvement}

Crowdfunding platforms are predominantly for-profit businesses, and their revenue model is based on a transaction fee for successful projects (Agrawal et al. 2013). Thus, they want to maximize the number and size of successful projects by attracting high-quality projects and many investors. When barriers to successful transactions arise, the platform has an incentive to step in to provide additional services to facilitate the transaction. These services include project accreditation, project recommendation, information gathering, project evaluation, project monitoring, community building (social networking), investor training, and reputation tracking. When a platform provides more services, it reduces the need for a third-party intermediary such as a lead investor. Thus, a pure crowd can be better supported without lead investors. Therefore,

Proposition 7 The higher the involvement of the platform in the investment process, the less advantageous a hybrid crowd is over a pure crowd.

That said, the platform may incur non-trivial costs for providing these services. For example, by hiring field agents to gather project information, the platform becomes more labor-intensive and less scalable. The platform may also undermine its neutral position by playing both investor and matchmaker.

\section{Managing lead investors}

\section{Why it is important for crowdfunding platforms to manage lead investors?}

In a hybrid crowd, lead investors have a great impact on crowd investors, project creators and crowdfunding platform. As information asymmetry always exists between crowd investors and project creators, crowd investors much leverage the expertise of lead investors to reduce such asymmetry. The quality of jobs such as due diligence and risk disclosure conducted by lead investors has a direct impact on crowd investors' investment judgement. As for project creators, endorsement by a prominent lead investor serves as signal of quality and impacts project success because lead investors have good investment records and reputation. At the platform side, lead investors can 
attract more crowd investors and promote project success, which aligns with platform's interests in maximizing revenue.

Because crowd investors tend to place great trust in lead investors, any imprudence, misrepresentation, or misconduct by lead investors may influence a crowdfunding market. Owing to the elevated power of lead investors and strong financial incentives attached, the management and regulation of lead investors require special attention. However, the literature on how to manage and regulate lead investors is scarce ${ }^{3}$. Based on this gap in the literature, our goal here is to summarize existing practices and highlight management and regulation challenges.

Lead investors may represent crowd investors (e.g., for conducting due diligence), project creators (e.g., for promoting and endorsing projects), and platforms (e.g., for identifying projects and promoting project success), so the management of lead investors can be analyzed by using the principle-agent framework, except that the situation here is complex because multiple principals exist. Hence, lead investors must be qualified and properly trained for their job through the use of selection and qualification mechanisms. Once they enter the role, they should be properly rewarded for desirable efforts and penalized for undesirable ones through disciplinary mechanisms. Table 2 summarizes some of the selection, compensation, and disciplining mechanisms used by hybrid crowd platforms.

\section{Selection mechanisms}

Lead investor qualification is both a management issue and a domain of law. While no special laws specify qualifications for lead investors, laws for qualified investors do exist. In the United States, for example, according to the JOBS Act (Title III), investment by crowd investors is limited within a 12-month period: if an investor's annual income or net worth is less than $\$ 100,000$, his or her investment limit is the greater of $\$ 2,000$ and $5 \%$ the lesser of the investor's annual income or net worth; if both annual income and net worth are equal to or more than $\$ 100,000$, then the investor's limit is $10 \%$ of the lesser of their annual income or net worth. Moreover, during the 12-month period, the aggregate amount of securities sold to an investor through all regulation crowdfunding offerings may not exceed $\$ 100,000$ regardless of the investor's annual income or net worth ${ }^{4}$. Although the JOBS Act enables more individuals in the United States to join crowdfunding, the barriers to entry globally are still high. For instance, in China, securities regulations define individuals with an annual income of $¥ 300,000$ or a net worth of $¥ 1$ million as accredited investors. To meet these financial criteria, accredited investors should be high-net-worth individuals such as angels or institutions such as venture capitalists and wealth management groups. All these basic requirements are also applicable to a qualified lead investor.

Table 2 Sample Platforms with Lead Investors

\begin{tabular}{|c|c|c|c|}
\hline Platform & Incentives for experts & Selection of experts & Risk control \\
\hline AngelList https://angel.co/ & Carry (20\%) & Accredited by platform & Lead, at least $20 \%$ of a deal \\
\hline 36kr https://36jr.com/ & Carry (20\%) & Accredited by platform & Lead, at least $20 \%$ of a deal \\
\hline JD Dongjia https://dj.jd.com/ & Carry (20\%) & Accredited by platform & Lead, at least $20 \%$ of a deal \\
\hline $\begin{array}{l}\text { AngelCrunch http:// } \\
\text { angelcrunch.com/ }\end{array}$ & Carry (20\%) & Accredited by platform & Lead, at least $20 \%$ of a deal \\
\hline
\end{tabular}


Within the framework of the law, platforms can implement their own rules for selecting accredited lead investors. On Yuanshihui, for example, the platform opens one position for a lead investor for each online venture project. All qualified investors, either an individual or institutional investor, can apply for the position by demonstrating their reasons and qualification. The platform also authorizes the project creator to select one lead from all applicants ${ }^{5}$. AngelList, by contrast, lets the lead select a project and bring it to the platform. Although it is easy to be an accredited investor in the United States, a set of rigorous criteria are provided by crowdfunding platforms such as AngelList to select leads who are qualified to launch syndicates.

A lead investor is supposed to work independently of the project in which he or she invests (just as auditors should be independent of the company they audit). Allowing a project creator to choose the lead grants the former implicit power to influence the lead (e.g., being influenced by flattery), thereby causing collusion concerns. There may be fewer concerns if leads are selected by the platform, which also has vested interests in maximizing funding successes. A crowd-selected lead thus seems to better align the interests of lead investors with its primary principle, namely crowd investors. However, no such case has thus far been implemented in any crowdfunding platform.

There are also the issues of who should qualify the lead investors and what criteria should be used. For example, should the platform or a third-party entity such as an association be the accreditation organization for lead investors? Should the accreditation criteria for lead investors be higher than that for crowd investors?

\section{Compensation mechanisms}

As lead investors are required to put in significant effort and take extra risk (e.g., 20\% investments), they need to be compensated more. The most common components of lead compensation include a service fee and a carry (recall that carried interest is a proportion of the proceeds from a successful exit). To earn the service fee, lead investors must conduct a set of duties for crowds such as carrying out due diligence, preparing investment documents, and disclosing risk. The service fee is paid when project funding succeeds, and it is usually $2 \%$ of the total funds raised. The carry is paid from the exit profits, usually accounting for $20-25 \%$.

The balance between the service fee and carry is an important issue. Because the probability of successful exits is much lower and more remote than that of successful funding, leads may be incentivized to earn the service fee, which is faster and easier, than waiting for the carry. Thus, this compensation structure may motivate the lead to conspire with the project creators to cheat money out of crowd investors.

Another issue with the lead compensation design is that a performance evaluation on the lead is lacking. If the lead does a poor job in due diligence reports, he or she may still receive his or her service fee. Furthermore, because the service fee is contingent on project success, it incentivizes the lead to exaggerate the prospect of the project so that he or she is more likely compensated. In an ideal setting, therefore, the service fee would be paid upon the delivery of a satisfactory service regardless of project funding success, while the crowd should be the judges of whether the service is satisfactory. 


\section{Disciplinary mechanisms}

Currently, leads are not penalized for inflating the prospects of a project or for producing a low-quality due diligence report. Indeed, it may be difficult to verify ex post that a lead purposefully misled crowd investors because of the inherent uncertainty of the outcome. However, if a lead deliberately withholds facts that he or she knows or lies about certain aspects of the project, he or she may still be held accountable.

The major problem is that platforms have no framework for imposing such a penalty. One potential approach would be to involve reputation mechanisms and exploit the power of a professional society/association. If cases of cheating and misconduct are reported to the professional association, this may harm a person's reputation, creating a credible threat. However, given the emerging nature of lead investors, it is unclear whether such "reputational concerns" could always be leveraged.

Certain dimensions of the lead investors' work such as the informativeness or thoroughness of their report may be readily assessable by crowd investors. Thus, their service fees may be tied to crowd investors' satisfaction. Currently, however, this is missing from the compensation design. Crowds may also be involved in selecting the lead investors from many candidates. Rules could also require lead investors to disclose their relevant performance history and any conflict of interests with the platform or project creator to ensure that crowd investors are equipped with the pertinent information to choose lead investors. Such disclosure is currently rather limited.

\section{Conclusion}

Motivated by the several inefficiencies of crowds in crowdfunding platforms, this study documents and compares two crowd designs: a popular pure crowd design and an emerging hybrid crowd design. Based on our observations of industry practices and the roles of crowds in crowdfunding platforms, we identify several of the shortcomings of pure crowds, including their ineffectiveness in providing heavy-duty due diligence, distortion in the wisdom of the crowds due to herding, social influence, and home bias, and high management costs associated with a lack of a single voice. Thus, pure crowds must be operated cautiously so that these shortcomings may be remedied. Based on our analysis of crowdfunding processes and the characteristics of crowd and lead investors, we identify a host of factors that may determine the optimal choice of crowd designs and present them in a framework for choosing between pure and hybrid crowds. Finally, given the potential problems in managing lead investors in hybrid crowds, we explore the issues of lead investor selection, compensation, and disciplining mechanisms and propose possible solutions.

As a first study of hybrid crowd design, this study contributes to the crowdfunding literature and to crowdfunding practice by opening the issue of crowd designs, recognizing hybrid crowd as a novel crowd design, and offering our insights into managing lead investors in hybrid crowds. Specifically, this study introduces the emerging hybrid crowd design and seeks to stimulate more research on this topic by outlining several testable hypotheses. Unlike previous studies that examine specific design elements in pure crowds (such as project length and community functionality), this study examines a high-level crowd design issue: choosing between pure and hybrid crowds in the context of crowdfunding. Our comparisons of pure and hybrid crowds can shed light on the evolution of crowd design in crowdfunding. In addition, both crowdfunding 
researchers and practitioners can benefit from our list of key driving factors behind the crowd design. Our discussion on the management of lead investors points to ways in which agency relationships in hybrid crowds could be further examined and opens a new door for the application of agency theory in crowdfunding.

This study leads to several promising avenues for future research. The most obvious one is to empirically test the propositions raised in this study. Second, the impact of lead investors on the crowdfunding platform, project creators, and crowd investors remains unclear. Third, our research points to potential agency problems in the investor relationships. Indeed, no regulation framework for such lead investors is present. Future research should thus aim to study lead investors and make further design and regulatory policy recommendations.

Based on our observations of crowdfunding platforms, we find that the degree of involvement by the crowdfunding platform in different activities can hold large implications for crowd and lead investors. For instance, crowdfunding platforms may develop tools that help individual investors gather information and provide decision support, which would reduce the crowd's need for a lead investor. Future research could investigate whether and how those tools improve crowdfunding effectiveness and efficiency.

Our study reveals the complex agency relationship among project creators, platform, lead investors, and crowd investors. Many problems could arise when intermediaries including the platform and lead investors have misaligned incentives. Although we suggested some practical solutions for managing and regulating lead investors, it remains worthwhile for future research to investigate how to design mechanisms that optimally align the incentives of different parties.

Our study has some limitations of which readers should be aware. First, we draw our conclusions based on industrial observations, a literature review, and informal arguments. An empirical analysis based on a carefully curated dataset would thus be a great complement to this study. Second, our conclusions are drawn based on generic crowdfunding practice, and we have not considered the differences in regulations and practices across countries (Gabison 2014). Readers may adjust our conclusions to their specific situations. Finally, while our conceptual framework of crowd design lists a number of key factors, it is not exhaustive. For instance, we have not considered the risk tolerance of investors or the risk control capability of the platform.

\section{Endnotes}

${ }^{1}$ The term "investor" used in this study can be interpreted as a lender, backer, and supporter depending on the type of crowdfunding. Similarly, a "project creator" can be interpreted as a borrower, seeker, and entrepreneur.

${ }^{2} \mathrm{~A}$ hybrid crowd is called a "syndicate" on the leading crowdfunding platform, AngelList.

${ }^{3}$ How to manage and regulate platforms is another important topic; however, this is outside the scope of the present study.

${ }^{4}$ The U.S. Securities and Exchange Commission, Regulation Crowdfunding: A Small Entity Compliance Guide for Issuers (May 13, 2016), Available at: https://www.sec.gov/ info/smallbus/secg/rccomplianceguide-051316.htm.

${ }^{5}$ On Yuanshihui as well as other equity platforms such as AngelList, lead and crowd investors typically form a Limited Liability Partnership in which the lead plays the role 
of the General Partner, while the other crowd investors act as Limited Partners. As required by the Companies Act in China, there can only be one General Partner. Therefore, Yuanshihui only allows one lead per project.

\section{Funding}

None.

\section{Availability of data and materials}

None.

\section{Authors' contributions}

All authors have contributed significantly to this paper. The specific areas of contribution are: LC: literature review, hypothesis development, conclusion. ZH: industry background and tables, management of lead investors, hypothesis development \& literature. DL: introduction, synthesis and improvement of different parts. All authors read and approved the final manuscript.

\section{Authors' information}

DL is an Associate professor of Information Decision Sciences Systems at Carlson School of Management, University of Minnesota. He received his PhD in Management Science and Information Systems from University of Texas at Austin, and his master's and bachelor's degree in Management Information Systems from Tsinghua University. His general research interests lie in combining economic thinking with sociological and psychological perspectives in analyzing and designing mechanisms for digital markets and platforms. His current research deals with economics of Internet auctions \& contests, gamification, social media and social commerce, crowdfunding and Internet finance. His research has appeared in MIS Quarterly, Information Systems Research, Journal of Marketing, and Journal of Market Research. He currently serves as an associate editor for Information Systems Research and Journal of Organizational Computing and Electronic Commerce.

LC is an assistant professor of computer information systems at West Texas A\&M University. He earned his PhD in Decision Science \& Information Systems from the University of Kentucky. He holds a B.A. and M.A. in business from Renmin University of China. His primary research interests include online reviews, crowdsourcing, knowledge management, and supplier development. His research has been published in notable journals such as Decision Support Systems, International Journal of Operations \& Production Management, and Journal of Electronic Commerce Research. He is an active reviewer of journals such as Information System Research, Journal of Organizational Computing and Electronic Commerce, and Journal of Electronic Commerce Research.

$\mathrm{ZH}$ is a FinTech researcher and a product manager at Yuanshihui Inc., an equity-crowd funding platform in China. He is involved in research and development of equity- and reward-based crowdfunding, and in current topics such as big data finance, robo-advisor, and blockchain. His research interests focus on the empowerment of investors in conventional financial markets by leveraging data science and information technology. He holds four degrees, including an electrical engineering bachelor from Southeast University, an economics bachelor from Peking University, an electronic engineering master from Tsinghua University, and a computer science master from University of Minnesota.

\section{Competing interests}

The authors declare that they have no competing interests.

\section{Author details}

${ }^{1}$ West Texas A\&M University, Canyon, TX, USA. ${ }^{2}$ Yuanshihui Inc., Floor 12, Zone A, Bldg Wangxin, No.28, Rd Xiaoyun, Chaoyang District, Beijing 100027, China. ${ }^{3}$ University of Minnesota, 3-163 Carlson School of Management, 321 19th Avenue South, Minneapolis, MN 55455, USA.

Received: 3 November 2016 Accepted: 24 November 2016

Published online: 05 December 2016

References

Adar E, Huberman BA (2000) Free riding on Gnutella. First Monday 5(10), available at: http://firstmonday.org/ojs/index. $\mathrm{php/fm/article/view/792/701.} \mathrm{Accessed} 10$ Nov 2016.

Agrawal A, Catalini C, Goldfarb A (2015) Crowdfunding: Geography, social networks, and the timing of investment decisions. J Econ Manage Strategy 24(2):253-274

Agrawal A, Catalini C, Goldfarb A (2016) Are Syndicates the Killer App of Equity Crowdfunding? Calif Manag Rev 58(2):111-124

Agrawal AK, Catalini C, Goldfarb A (2011) The geography of crowdfunding, NBER Working Paper no. 16820, available at: http://www.nber.org/papers/w16820. Accessed 10 Nov 2016

Agrawal AK, Catalini C, Goldfarb A (2013) Some simple economics of crowdfunding. NBER Working Paper, No. 19133. Available at: http://www.nber.org/papers/w19133. Accessed 10 Nov 2016.

Ahlers GK, Cumming D, Günther C, Schweizer D (2015) Signaling in equity crowdfunding. Enterp Theory Pract 39(4):955-980

Banerjee AV (1992) A simple model of herd behavior. Q J Econ 107(3):797-817

Belleflamme P, Lambert T (2014) Crowdfunding: Some empirical findings and microeconomic underpinnings. Available at: http://ssrn.com/abstract=2437786. Accessed 10 Nov 2016.

Byrne K (2005) How do consumers evaluate risk in financial products? J Financ Serv Mark 10(1):21-36

Coppey $L$ (2016) From value-added VCs to equity crowdfunding syndicates: the new platforms of the venture capital industry. Cambridge, MA: Massachusetts Institute of Technology. http://hdl.handle.net/1721.1/104539. Accessed 10 Nov 2016. 
Deschler GD (2013) Wisdom of the intermediary crowd: what the proposed rules mean for ambitious crowdfunding intermediaries. Saint Louis Univ Law J 58:1145-1187

Diacon S (2004) Investment risk perceptions: Do consumers and advisers agree? Int J Bank Market 22(3):180-199 Fried VH, Hisrich RD (1994) Toward a model of venture capital investment decision making. Financ Manag 23(3):28-37 Fuglseth AM, Grønhaug K (1995) Task characteristics and expertise. In: Green B (ed) Problem solving and cognitive processes. Fagbokforlaget, Bergen, pp 513-529

Gabison GA (2014) Equity Crowdfunding: All Regulated But Not Equal. DePaul Bus Commercial Law J 13(3):359-409 Glaser M, Weber M (2007) Overconfidence and trading volume. Geneva Risk Insur Rev 32(1):1-36

Hekman E, Brussee R (2013) Crowdfunding and online social networks. 2nd Consortium on Applied Research and Professional Education. Manchester, UK. Utrecht, Netherlands: CARPE (the Consortium on Applied Research and Professional Education).

Kim K, Viswanathan S (2014) The experts in the crowd: The role of reputable investors in a crowdfunding market Available at SSRN: https://ssrn.com/abstract=2258243. Accessed 10 Nov 2016.

Krishnan R, Smith MD, Telang R (2003) The economics of peer-to-peer networks. Available at SSRN: https://ssrn.com/ abstract=504062. Accessed 10 Nov 2016.

Lewis G (2011) Asymmetric information, adverse selection and online disclosure: The case of eBay motors. Am Econ Rev 101(4):1535-1546

Lin M, Viswanathan S (2015) Home bias in online investments: An empirical study of an online crowdfunding market. Manag Sci 62(5):1393-1414

Liu D, Brass D, Lu Y, Chen D (2015) Friendships in online peer-to-peer lending: Pipes, prisms, and relational herding. MIS Q 39(3):729-742

Lorenz J, Rauhut H, Schweitzer F, Helbing D (2011) How social influence can undermine the wisdom of crowd effect. Proc Natl Acad Sci 108(22):9020-9025

Malmendier U, Shanthikumar D (2007) Are small investors naive about incentives? J Financ Econ 85(2):457-489

Mollick E (2014) The dynamics of crowdfunding: an exploratory study. J Bus Ventur 29(1):1-16

Mollick E, Nanda R (2016) Wisdom or madness? Comparing crowds with expert evaluation in funding the arts. Manag Sci 62(6):1533-1553

Moritz A, Block J, Lutz E (2015) Investor communication in equity-based crowdfunding: a qualitative-empirical study. Qual Res Financ Markets 7(3):309-342

Rose N (2016) How to Crowdfund Without a Lead Investor. in: Crowdsourcing Week, available at: http:// crowdsourcingweek.com/blog/equity-crowdfunding-with-no-lead-investor/. Accessed 10 Nov 2016.

Salganik MJ, Dodds PS, Watts DJ (2006) Experimental study of inequality and unpredictability in an artificial cultural market. Science 311(5762):854-856

Surowiecki J (2004) The Wisdom of Crowds: Why the Many are Smarter Than the Few and how Collective Wisdom Shapes Business, Economies, Societies, and Nations, Doubleday, New York.

Vismara S (2015) Information cascades among investors in equity crowdfunding. Available at: https://ssrn.com/abstract= 2589619. Accessed 10 Nov 2016

Wilson KE, Testoni M (2014) Improving the role of equity crowdfunding in Europe's capital markets. Bruegel Policy Contribution, available at: http://ssrn.com/abstract=2502280. Accessed 10 Nov 2016.

Wortham J (2012) Success of Crowdfunding Puts Pressure on Entrepreneurs. in: The New York Times. Available at: http://www.nytimes.com/2012/09/18/technology/success-of-crowdfunding-puts-pressure-on-entrepreneurs.html. Accessed 10 Nov 2016.

Zhang J (2013) The wisdom of crowdfunding. Communities and Banking, Winter Issue: 30-31.

Zhang J, Liu P (2012) Rational herding in microloan markets. Manag Sci 58(5):892-912

Zhunussov B (2015) Crowdfunding: Literature Study for Communication and Information Asymmetry (September 1, 2015) Available at SSRN: https://ssrn.com/abstract=2717274. Accessed 10 Nov 2016

Zvilichovsky D, Inbar Y, Barzilay O (2013) Playing Both Sides of the Market: Success and Reciprocity on Crowdfunding Platforms. The 34th International Conference on Information Systems. Milano, Italy. Atlanta, GA: AIS (The Association for Information Systems).

\section{Submit your manuscript to a SpringerOpen ${ }^{\circ}$ journal and benefit from:}

- Convenient online submission

- Rigorous peer review

- Immediate publication on acceptance

- Open access: articles freely available online

- High visibility within the field

Retaining the copyright to your article 